\title{
Assessing surface albedo change and its induced radiation budget under rapid urbanization with Landsat and GLASS data
}

\begin{abstract}
Radiative forcing (RF) induced by land use (mainly surface albedo) change is still not well understood in climate change science, especially the effects of changes in urban albedo due to rapid urbanization on the urban radiation budget. In this study, a modified RF derivation approach based on Landsat images was used to quantify changes in the solar radiation budget induced by variations in surface albedo in Beijing from 2001 to 2009. Field radiation records from a Beijing meteorological station were used to identify changes in RF at the local level. There has been rapid urban expansion over the last decade, with the urban land area increasing at about $3.3 \%$ annually from 2001 to 2009. This has modified three-dimensional urban surface properties, resulting in lower albedo due to complex building configurations of urban centers and higher albedo on flat surfaces of suburban areas and cropland. There was greater solar radiation (6.93 $\mathbb{\text { X }}$ Glll08 W) in the urban center in 2009 than in 2001. However, large cropland and urban fringe areas caused less solar radiation absorption. RF increased with distance from the urban center (less than $14 \mathrm{~km}$ ) and with greater urbanization, with the greatest value being $0.41 \mathrm{~W} / \mathrm{m} 2$. The solar radiation budget in urban areas was believed to be mainly influenced by urban structural changes in the horizontal and vertical directions. Overall, the results presented herein indicate that cumulative urbanization impacts on the natural radiation budget could evolve into an important driver of local climate change.
\end{abstract}

Keyword: Albedo; Landsat; Radiative forcing (RF); Climate change; Urbanization 